\title{
Estimation of Suspended Sediment Concentration from Remote Sensing and In Situ Measurement over Lake Tana, Ethiopia
}

\author{
Zelalem R. Womber ${ }^{D},{ }^{1}$ Fasikaw A. Zimale ${ }^{1},{ }^{1}$ Mebrahtom G. Kebedew, ${ }^{1}$ Bekalu W. Asers, ${ }^{1}$ \\ Nikole M. DeLuca, ${ }^{2}$ Christian D. Guzman $\mathbb{D D}^{3}{ }^{3}$ Seifu A. Tilahun $\mathbb{D D}^{1}{ }^{1}$ \\ and Benjamin F. Zaitchik $\mathbb{D}^{2}$ \\ ${ }^{1}$ Bahir Dar Institute of Technology, Bahir Dar University, Bahir Dar, Ethiopia \\ ${ }^{2}$ Johns Hopkins University, Earth and Planetary Sciences, Baltimore, USA \\ ${ }^{3}$ Civil and Environmental Engineering, University of Massachusetts, Amherst, MA, USA
}

Correspondence should be addressed to Fasikaw A. Zimale; fasikaw@gmail.com

Received 19 March 2021; Revised 29 June 2021; Accepted 7 July 2021; Published 22 July 2021

Academic Editor: Mosbeh Kaloop

Copyright (c) 2021 Zelalem R. Womber et al. This is an open access article distributed under the Creative Commons Attribution License, which permits unrestricted use, distribution, and reproduction in any medium, provided the original work is properly cited.

\begin{abstract}
Discharge from basins joining a lake is the main factor determining the lake volume and sediment inflow to the lake. Suspended sediment is an important parameter for describing the water quality of aquatic ecosystems. Lake Tana is an important and the largest lake in Ethiopia for the local ecological system. However, environmental change and anthropogenic activities in the area threaten its water quality. The conventional methods of suspended sediment concentration (SSC) observation are unable to determine and compare spatial and temporal SSC patterns for the lake over a period of years. Remote sensing methods have made it possible to map SSC. The objective of this study is to characterize the spatial and temporal distribution of suspended sediment of Lake Tana using in situ measurement and remote sensing applications and specifically to develop a relationship between in situ and remote sensing observation to retrieve suspended sediment concentration and map the spatal distribution of SSC. This study used MODIS-Terra and in situ data to characterize the spatial and temporal distribution of SSC in the rainy season. Four sampling campaigns ( 20 samples per campaign) were carried out on Lake Tana, and the first three sampled campaigns on May 11-13, 2018, June 08-10, 2018, and July 15-17, 2018, were used for calibration of regression models. MODIS-Terra reflectance in NIR was found best related to in situ water quality data and varies linearly with SSC $\left(r^{2}=0.81\right)$ and turbidity $\left(r^{2}=0.85\right)$. Secchi disc depth (SDD) found the best fit for a power relation with NIR band reflectance $\left(r^{2}=0.74\right)$. The MODIS-Terra reflectance in red was found to be poorly related to in situ measurements. The relation in NIR reflectance was validated using the LOOCV (leave-one-out-cross-validation) technique and the fourth sampled data set collected on August 12-14, 2018. Developed models are validated with RMSE of $42.96 \mathrm{mg} / \mathrm{l}, 14.6 \mathrm{NTU}$, and $0.17 \mathrm{~m}, \mathrm{ARE}$ of $23.3 \%, 27.6 \%$, and $12.4 \%$, and RRMSE of $25.1 \%, 44.5 \%$, and $29.6 \%$ for SSC, turbidity, and SDD, respectively, using LOOCV. The equation was also validated using August 2018 collected data sets with RMSE of $87.6 \mathrm{mg} / \mathrm{l}, 11.7 \mathrm{NTU}, 0.08 \mathrm{~m}$, ARE of $20.8 \%, 25.9 \%$, and $28.8 \%$, and RRMSE of $17.8 \%, 20.5 \%$, and $27.9 \%$ for SSC, turbidity, and SDD, respectively. Applying the developed regression model, a 10-year time series of SSC from 2008-2017 for May-August was estimated and the trend was tested using the Mann-Kendall trend test. It was found that an increasing trend was observed from the period 2008 to 2017. The result shows that satellite data like the MODIS-Terra imagery could be used to monitor and obtain past records of SSC with the developed equation. The increasing SSC can be reduced by implementing selected management practices in the surrounding watersheds of the lake to reduce nutrient and sediment inflow.
\end{abstract}

\section{Introduction}

Discharge from basins entering a lake is the main determinant of the lake volume and sediment inflow into the lake. Suspended sediment concentration is an important parameter for describing lake water quality [1]. Water transports suspended sediments/solids, nutrients, and contaminants, which again reduce light transmission through a water column and influence entire aquatic ecosystems [1-3]. 
The process of conventional methods for water quality monitoring over a lake mainly includes the collection and laboratory analysis of water samples. These conventional methods are more precise, but they are carried out with limited water samples over space and time, thus may not reflect the overall lake water quality [4]. They are not only limited in their spatial and temporal coverage but also timeconsuming and expensive [4-9]. In this paper, site-specific relationships are developed for mapping suspended sediment concentration (SSC), turbidity, and Secchi disc depth on Lake Tana. The relationship developed for SSC is used to generate a ten-year time series of SSC for Lake Tana.

The development of remote sensing techniques has made it possible to monitor optically active substances such as suspended sediments/or solids in a waterbody [10]. Over recent decades, a number of studies have demonstrated that suspended matter distribution in inland waters can be mapped from various types of satellite remote sensing data, such as Landsat TM, Landsat ETM+, and Landsat-8, Moderate Resolution Imaging Spectroradiometer (MODIS), Medium Resolution Imaging Spectrometer (MERIS), Advanced Very High-Resolution Radiometer (AVHRR), SeaViewing Wide Field-of-view Sensor (SeaWiFS), and Satellite Pour I'Observation de la Terre (SPOT) [4-9, 11]. Previous studies have proposed Landsat-7 ETM+ and Landsat-8 bands as a spectral self-phase modulation (SPM), turbidity, and Secchi disc depth (SDD) indicator for Lake Tana $[5,8]$, but its limitation on the temporal resolution is insufficient for the study of dynamic changes of sediment. Kaba et al. [7] used Terra-MODIS to investigate the relationship between water quality parameters and Terra-MODIS derived reflectance only at Gumara river inlet to Lake Tana. However, this study uses the Terra-MODIS derived reflectance data over the whole lake area to investigate the relationship with water quality parameters.

In this study, MODIS-Terra daily surface reflectance data and in situ data were used to develop a relationship and estimate past records of SSC for Lake Tana in the Blue Nile Basin. MODIS-Terra has high temporal resolution and is more sensitive than Landsat-7 ETM + satellite images [12]. Moreover, satellite-derived images of suspended sediment can be retrieved using single or a combination of band algorithms based on reflectance spectral regions [5, 7-10]. The essential part of quantifying SSC using a remote sensing approach is that the model infers SSC from remotely sensed information. Ma et al. [13] and Wang et al. [11] classified models as empirical, semiempirical, and analytical models. Empirical models normally establish the relationship between apparent optical properties (i.e., remote sensing reflectance) and inherent optical properties (i.e., suspended sediment) directly by statistical analysis such as linear and nonlinear regression. A number of studies have been applied in such models for estimating and retrieving water quality across the world $[1,5,7-9,11,14-23]$.

\section{Methodology}

2.1. Study Area. Lake Tana is located at $12^{\circ} 01^{\prime} 35^{\prime \prime} \mathrm{N}$ latitude and $037^{\circ} 18^{\prime} 12^{\prime \prime} \mathrm{E}$ longitude or located in the northwest of the Ethiopian highlands (Figure 1). The lake is the source of the Blue Nile and the largest lake in Ethiopia [2, 8]. The lake is found in a wide depression of the Ethiopian basaltic plateau and is bordered by flood plains that are often flooded during the rainy season. The flood plains bounding the lake are the Fogera flood plain in the east (mainly by Gumara and Rib rivers), the Dembia flood plain in the north (from Megech river), and the Kunzila flood plain in the southwest (mainly associated with Gilgel Abay, Kelti, and Koga river), while it is bordered by steep rocks in the west and northwest $[2]$.

It is a shallow lake with a mean depth of $9 \mathrm{~m}$ and a maximum depth of $15 \mathrm{~m}$. The lake is approximately $84 \mathrm{~km}$ long and $66 \mathrm{~km}$ wide with an elevation of $1800 \mathrm{~m}$ [7]. The lake has an average temperature of $22^{\circ} \mathrm{C}$ and a mean annual rainfall of $1450 \mathrm{~mm} /$ year [8]. Lake Tana is fed by the Gilgel Abbay, Rib, Megech, and Gumara rivers [2, 3]. The estimated mean annual flow to Lake Tana from Gilgel Abbay is $1810 \mathrm{~mm}^{3}$, Gumara is $930 \mathrm{~mm}^{3}$, Rib is $430 \mathrm{~mm}^{3}$, and Megech is $189 \mathrm{~mm}^{3}$. The mean annual inflow to the lake is estimated to be $158 \mathrm{~m}^{3} / \mathrm{s}$ [24], with the largest flow coming from the Gilgel Abbay river. The lake's surface area ranges from 3000 to $3600 \mathrm{~km}^{2}$ [5], depending on the season and rainfall. The lake level has been regulated since the construction of the Chara Chara control weir. These controls flow to the Blue Nile Falls and a hydropower station [25].

2.2. Materials and Methods. Four field trips were conducted in 2018 from 11-13 May, 08-10 June, 15-17 July, and 12-14 August to measure Secchi disc depth (SDD) and collect water samples at 20 monitoring points on the lake at $0.2 \mathrm{~m}$ depth with Van Dorn water sampler [7]. The sampling dates were spread within those months to capture variations in sediment inflow. For each sampling point, GPS coordinates were taken on the specified location of the lake to enable the collection of water quality data at the same place at different times. The points were selected to show the spatiotemporal distribution of suspended sediment when the major tributary rivers (i.e., Gilgel Abay, Gumara, Rib, and Megech rivers) fed the lake during the wet season. The sampling points are shown in Figure 2.

2.2.1. SSC, Turbidity, and SDD Measurements. The determination of suspended sediment concentration (SSC) was performed by filtration of the sampled 1 liter of water using a Whatman $320 \mathrm{~mm}$ diameter filter paper and oven drying for 24 hours at $105^{\circ} \mathrm{C}$ and subtracting weight of the dried filter and sediment to the filter weight divided by the sampling volume of water [26]. Turbidity was determined by a Hach $2100 \mathrm{~N}$ turbidimeter after calibrating using a 0.1-7500 NTU formazin standard solution provided with the kit [7]. Secchi disc depth (SDD) measurement was observed using a $20 \mathrm{~cm}$ diameter Secchi disc (SD) to determine the depth to which visibility remained clear. The disc was submerged using a gaged rope and depths where the disk could no longer be seen from the surface with the naked eye was recorded $[8,27,28]$. 


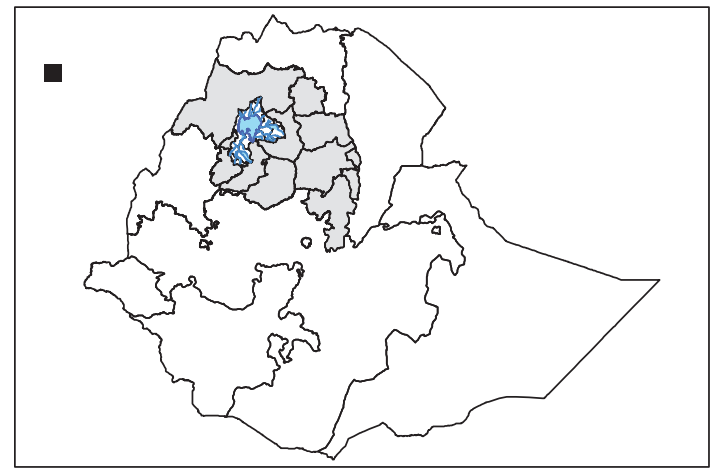

(a)

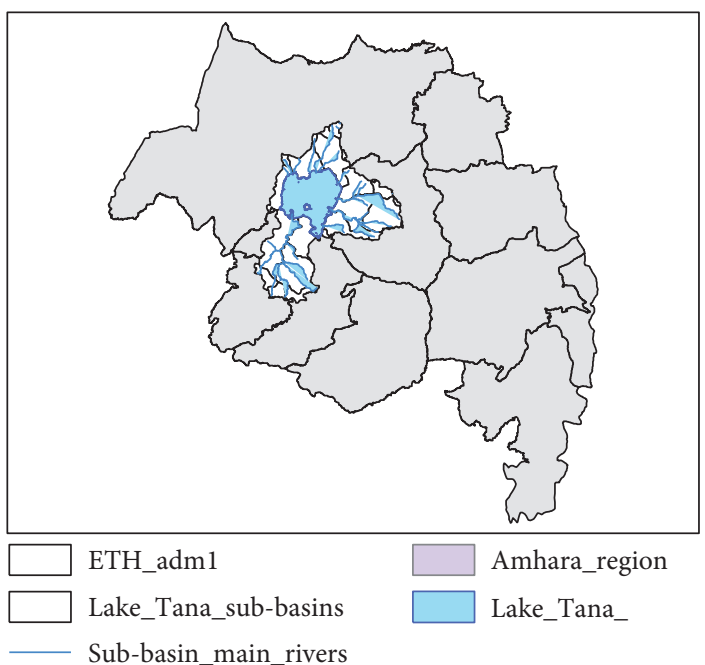

(b)

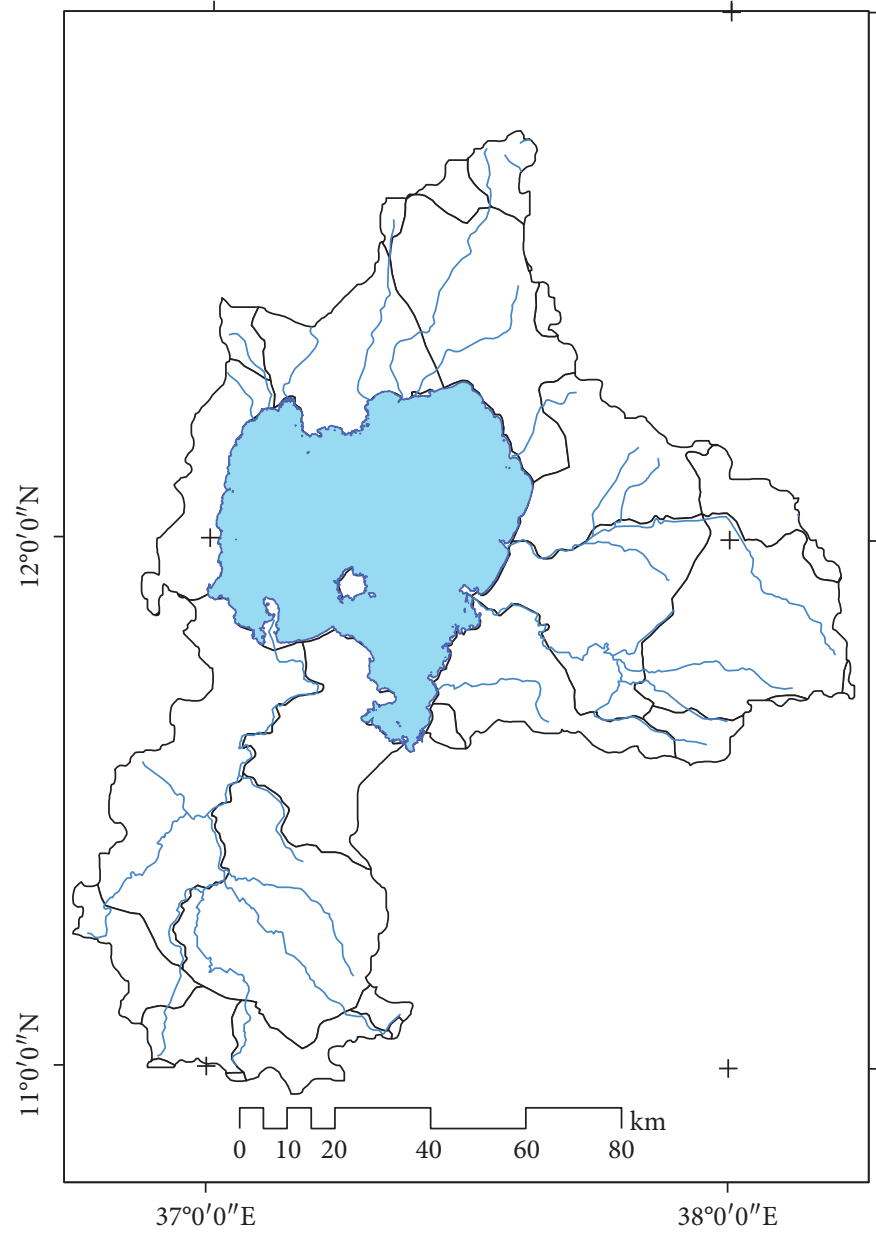

(c)

Figure 1: Major contributing rivers and location map of Lake Tana Basin: (a) Ethiopian regions; (b) Amhara region; (c) Lake Tana Basin.

2.2.2. MODIS-Terra Data Acquisition. The MODIS-Terra images have been acquired in 36 spectral bands with $250 \mathrm{~m}$, $500 \mathrm{~m}$, and $1,000 \mathrm{~m}$ spatial resolutions. The red $(620-670 \mathrm{~nm})$ and NIR $(841-876 \mathrm{~nm})$ bands labeled “MOD09GQ" version 6 surface reflectance data are available on a daily basis at $250 \mathrm{~m}$ spatial resolution [29]. The acquisition of MODIS-Terra data was concurrent with in situ measurements obtained on the lake. The satellite image was downloaded from USGS (https://lpdaacsvc.cr.usgs.gov/) site in GeoTIFF and projected to coordinates via the Application for Extracting and Exploring Analysis Ready Samples (AppEEARSs) which is free and was conducted for each sampling date. 12 May and 15 July 2018 were cloudy days, and MOD09GQ daily surface reflectance data were not acquired. To show the turbidity plum of the lake with RGB color during the wet-dry (May-Sep) season, MOD09GA MODIS-Terra images were used. MOD09GA provides MODIS band 1-7 daily surface reflectance at $500 \mathrm{~m}$ resolution and $1 \mathrm{~km}$ observation and geolocation statistics. The RGB image is composed of surface reflectance measured by MODIS bands 1 (red), 4 (green), and 3 (blue) with wavelength range of $620-670 \mathrm{~nm}, 545-565 \mathrm{~nm}$, and $459-479 \mathrm{~nm}$, respectively [30].
2.2.3. Calibration and Validation of Regression Models. Following the work of $[7,9]$, several combinations of bands were tested along with a single band. The goodness of fit of the developed models was evaluated based on the coefficient of determination $\left(R^{2}\right)$. The three months (i.e., May, June, and July 2018) data sets excluding the cloudy days were used to calibrate or develop the regression model. For the validation of the model, the leave-one-outcross-validation (LOOCV) technique was employed $[1,9]$. The leave-one-out-cross-validation (LOOCV) technique works as follows. The first sample data point in the sample used in developing the regression model is excluded, and the others were used as training data to develop a correlation between $Y$ and $X$ using the least-squares regression.

The slope, intercept, and $R^{2}$ values of the resulting relation are recorded, and then the equation is used to estimate $Y$ of the excluded sample from $X$. This procedure was repeated by excluding all sample points, one by one for SSC, turbidity, and SDD. This will produce a series of slope values, intercept values, $R^{2}$ values, and estimated $Y$ values, which were useful for assessing the accuracy of the calibration model. Accuracies of predicted SSC, turbidity, and SDD 


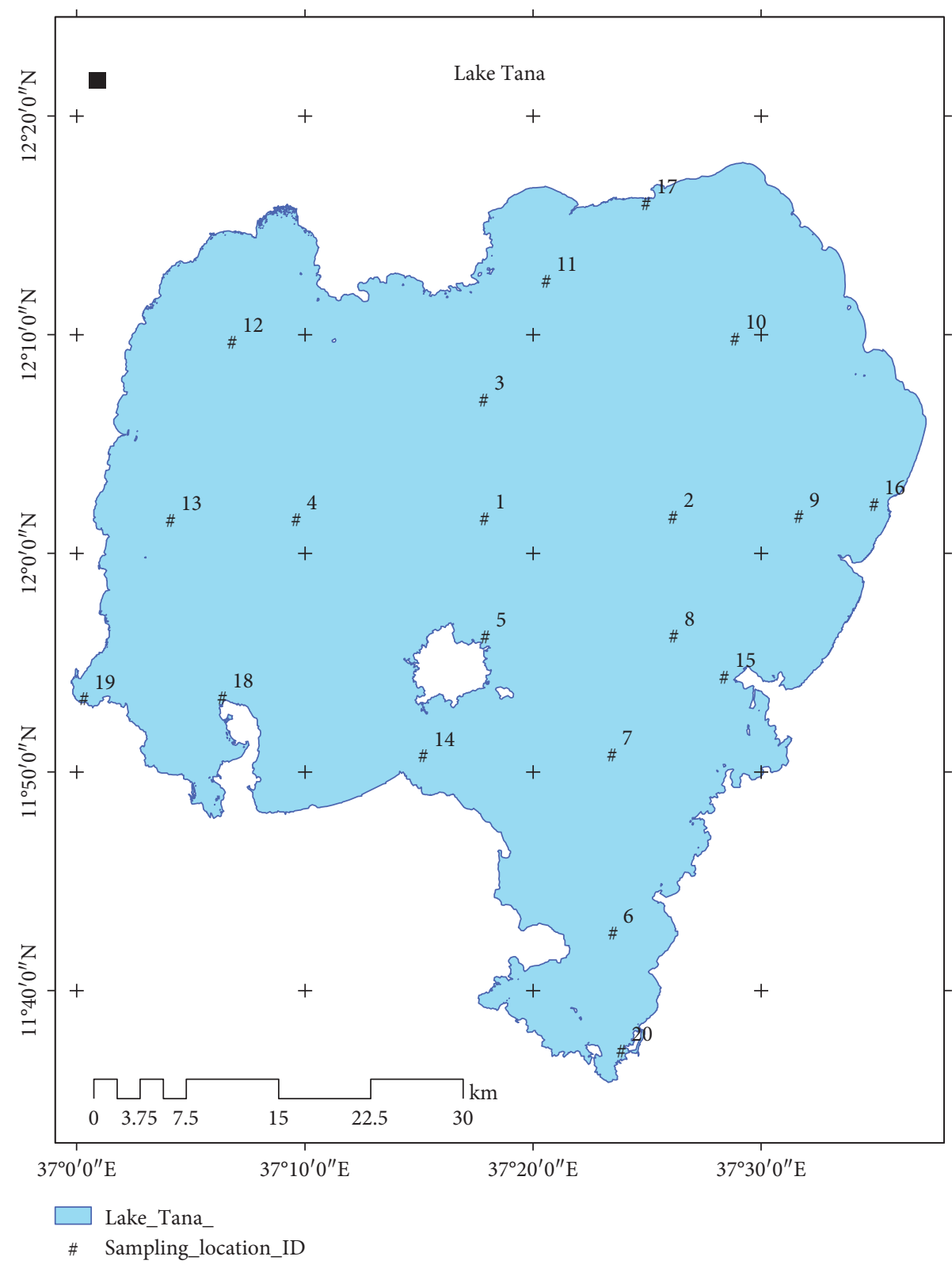

FIgURe 2: Sampling locations on Lake Tana.

were assessed by the root mean square error (RMSE), relative root mean square error (RRMSE), and absolute relative error (ARE) as follows:

$$
\begin{aligned}
\text { RMSE } & =\sqrt{\frac{\sum\left(X_{o}-X_{E}\right)^{2}}{n},} \\
\text { RRMSE } & =\frac{\text { RMSE }}{\left(\sum X_{o} / n\right)} * 100 \%, \\
\text { ARE } & =\left|\frac{X_{o}-X_{E}}{X_{o}} * 100 \%\right| .
\end{aligned}
$$

\section{Results}

3.1. SSC, Turbidity, and SDD vs. MOD09GQ Reflectance Relationships. The descriptive summary of the observed values of water quality variables for the sampled months is given in Table 1. In order to obtain the desired relationship between the MODIS-Terra daily surface reflectance data and in situ observations, the reflectance values of downloaded MOD09GQ data were extracted on the sampling points using the ArcGIS spatial analysis tool as the images are already corrected for atmospheric, gaseous, and aerosol effects [29]. Table 2 summarizes all the combinations of relationships between the in situ observed and the MODISTerra remote sensing reflectance data. 
TABle 1: Descriptive statistics of measured SSC, turbidity, and SDD from the surface of Lake Tana for sampled campaigns.

\begin{tabular}{|c|c|c|c|c|}
\hline Descriptive statistics & May & June & July & August \\
\hline \multicolumn{5}{|l|}{$S S C(m g / l)$} \\
\hline Mean & 205.7 & 190.8 & 377.4 & 422.7 \\
\hline Median & 181.7 & 154.1 & 169.9 & 228.6 \\
\hline Standard deviation & 89.4 & 92.2 & 470.5 & 435.8 \\
\hline Minimum & 113.1 & 107.6 & 108.2 & 104 \\
\hline Maximum & 375.9 & 375.2 & 1661.3 & 1519.2 \\
\hline Count & 20 & 20 & 20 & 20 \\
\hline \multicolumn{5}{|l|}{ Turbidity (NTU) } \\
\hline Mean & 20.10 & 41.24 & 91 & 72.07 \\
\hline Median & 14.60 & 20.00 & 50 & 54.85 \\
\hline Standard deviation & 15.18 & 45.02 & 125 & 57.52 \\
\hline Minimum & 7.30 & 12.70 & 14 & 16.80 \\
\hline Maximum & 68.60 & 178.0 & 558 & 253.0 \\
\hline Count & 20 & 20 & 20 & 20 \\
\hline \multicolumn{5}{|l|}{$S D D(m)$} \\
\hline Mean & 0.78 & 0.56 & 0.40 & 0.31 \\
\hline Median & 0.82 & 0.62 & 0.27 & 0.26 \\
\hline Standard deviation & 0.29 & 0.27 & 0.22 & 0.18 \\
\hline Minimum & 0.28 & 0.06 & 0.13 & 0.09 \\
\hline Maximum & 1.50 & 0.87 & 0.84 & 0.75 \\
\hline Count & 20 & 20 & 20 & 20 \\
\hline
\end{tabular}

TABLE 2: $R^{2}$, adjusted $R^{2}$, standard error, and significance $F$ of SSC, turbidity, and SDD estimates of different regressions for various combinations of bands.

\begin{tabular}{|c|c|c|c|c|}
\hline Band combinations & $R^{2}$ & Adjusted $R^{2}$ & Standard error & Significance $F$ \\
\hline \multicolumn{5}{|l|}{$\operatorname{SSC}(m g / l), n=30$} \\
\hline Red & 0.75 & & 45.95 & 0.0000 \\
\hline NIR & 0.81 & & 25.48 & 0.0000 \\
\hline Red - NIR & 0.78 & 0.78 & 33.32 & 0.0000 \\
\hline Red + NIR & 0.53 & 0.51 & 89.30 & 0.0000 \\
\hline NIR/red & 0.56 & 0.55 & 75.65 & 0.0000 \\
\hline NDVI (red-NIR/red + NIR) & 0.54 & 0.52 & 82.39 & 0.0000 \\
\hline \multicolumn{5}{|l|}{ Turbidity (NTU), $n=27$} \\
\hline Red & 0.84 & & 4.00 & 0.0000 \\
\hline NIR & 0.85 & & 2.80 & 0.0000 \\
\hline Red - NIR & 0.85 & 0.84 & 3.25 & 0.0000 \\
\hline Red + NIR & 0.65 & 0.64 & 7.75 & 0.0000 \\
\hline NIR/red & 0.78 & 0.77 & 6.27 & 0.0000 \\
\hline NDVI (red-NIR/red + NIR) & 0.71 & 0.69 & 7.60 & 0.0000 \\
\hline \multicolumn{5}{|l|}{$S D D(m), n=31$} \\
\hline Red & 0.72 & & 0.04 & 0.0000 \\
\hline NIR & 0.74 & & 0.03 & 0.0000 \\
\hline Red - NIR & 0.73 & 0.72 & 0.04 & 0.0000 \\
\hline Red + NIR & 0.43 & 0.42 & 0.06 & 0.0003 \\
\hline NIR/red & 0.71 & 0.7 & 0.05 & 0.0000 \\
\hline NDVI (red-NIR/red + NIR) & 0.70 & 0.69 & 0.04 & 0.0000 \\
\hline
\end{tabular}

The band explaining the best relationship with the parameter has the highest R2 and lowest standard error, which is indicated in bold.

In all band combinations, a linear relationship was observed between the tested red and NIR combinations of MODIS bands and SSC, turbidity, and SSD. In this study, it was found that the relationship between MODIS reflectance to the NIR band was superior to other combinations. This was in agreement with previous studies [7, 9]. For instance, a study conducted by Kaba et al. [7] reported that the NIR band was superior to other combinations of red and NIR bands as an indicator of TSS, turbidity, and Secchi disc on Lake Tana, Ethiopia. The calibrated regression equations between SSC, turbidity, SDD, and the MODIS reflectance are given as equations (2)-(4) and shown in Figures 3-5.

$$
\mathrm{SSC}=2195.9 * \rho \mathrm{NIR}+74.3,
$$

where SSC is in $\mathrm{mg} / \mathrm{l}, n=30, p<0.001$, and $r^{2}=0.81$. 


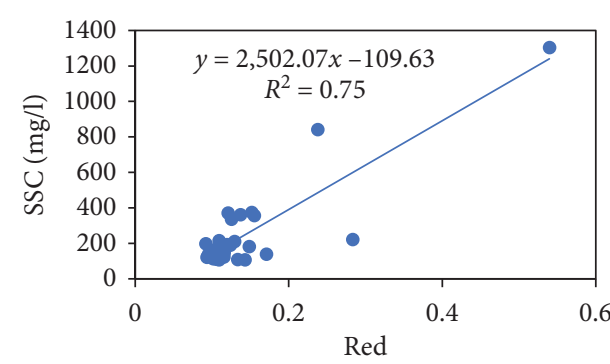

(a)

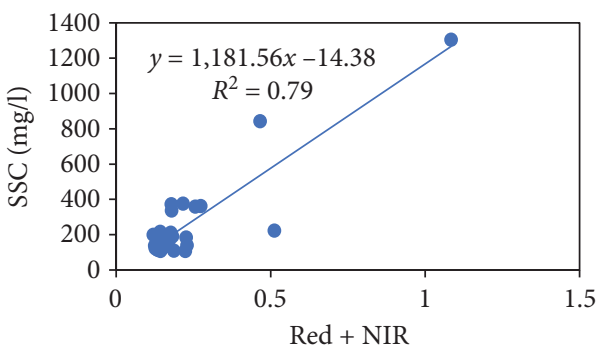

(c)

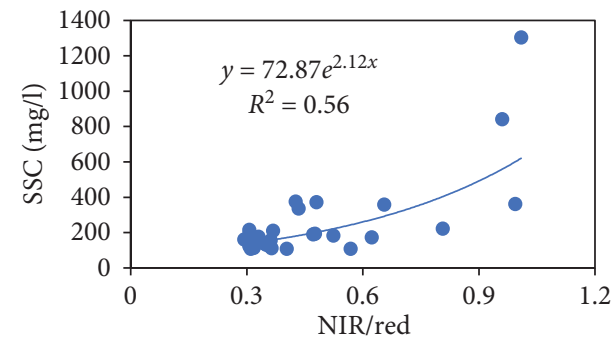

(e)

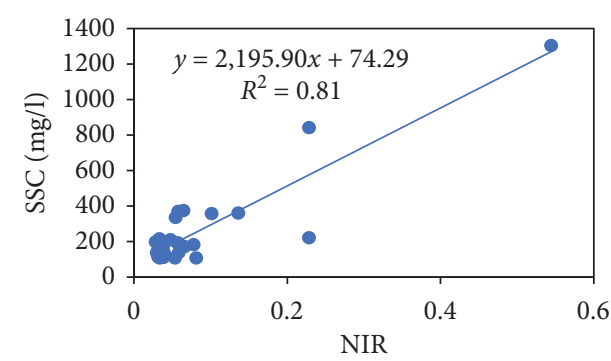

(b)

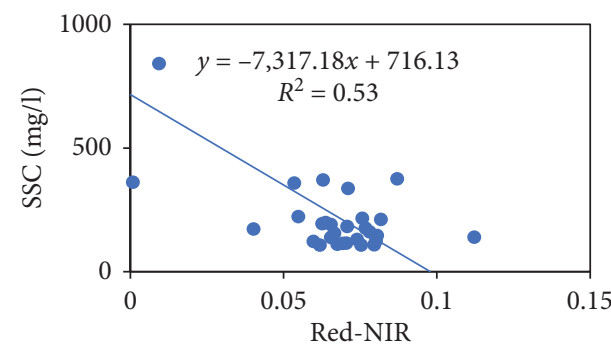

(d)

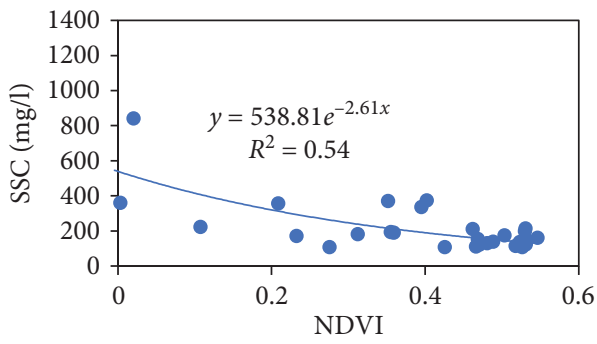

(f)

FIGURE 3: Scatter plot of observed SSC (mg/l) against MOD09GQ surface reflectance bands: (a) SSC vs. red band; (b) SSC vs. NIR band; (c) SSC vs. (red + NIR) band; (d) SSC vs. (red-NIR) band; (e) SSC vs. (NIR/red) band; (f) SSC vs. (red-NIR/red + NIR) or NDVI band.

$$
\text { Turbidity }=186.4 * \rho \mathrm{NIR}+13.3
$$

where turbidity is in NTU, $n=27, p<0.001$, and $r^{2}=0.85$.

$$
\mathrm{SDD}=0.1543 * \rho \mathrm{NIR}^{-0.455} \text {, }
$$

where SDD is in $\mathrm{m}, n=31, p<0.001$, and $r^{2}=0.74$.

From the above equations, $p \mathrm{NIR}, n, p$, and $r^{2}$ are reflectance of the near-infrared band, the numbers of samples used to build the model, the probability that such a linear relation is occurring by chance (at $5 \%$ level of significance), and the coefficient of determination of the fit, respectively.

In the NIR, where the absorption is predominantly due to water and the scattering is predominantly due to the suspended matter, it is reasonable to expect that the reflectance would be roughly linearly proportional to measures of the suspended sediment load as long as the scattering properties are consistent over the range of observations [7].

3.2. Validation of Regression Models. This study applied regression analysis to develop the relation with SSC, turbidity, and SDD vs. reflectance on Lake Tana from data collected in May, June, and July (i.e., equation (2)-(4)). These models were then validated with two different ways.
The first is using the leave-one-out-cross-validation (LOOCV) technique, and the second is using the predicted values from the August 2018 reflectance with the developed model versus August 2018 collected datasets which have never been used for the calibration. LOOCV has been widely used in remote sensing studies [1,9] because the estimated samples are different from the samples used to develop the regression model.

All of the samples $n=30$ for SSC, $n=27$ for turbidity, and $n=31$ for SDD are used for calibrating the model. The series of intercept values $a$, slope values $b$, and $R^{2}$ values produced during iteration in the LOOCV technique showed little variation. The scatter plot of the observed versus estimated and observed versus residuals is shown in Figure 6.

The estimation errors were found with the ARE of $23.3 \%$, $27.6 \%$, and $12.4 \%$, with a RMSE of $42.9 \mathrm{mg} / 1,14.6 \mathrm{NTU}$, and $0.17 \mathrm{~m}$, and a RRMSE of $25.1 \%, 44.5 \%$, and $29.6 \%$ for SSC, turbidity, and SDD, respectively. The residuals are distributed in between $\pm 60 \mathrm{mg} / \mathrm{l}$ for SSC, \pm 20 NTU for turbidity, and $\pm 0.2 \mathrm{~m}$ for SDD (Figure 6). Applying these developed regression models to August 2018 datasets produced an estimation error of ARE of $20.8 \%, 25.9 \%$, and $28.8 \%$ and RMSE of $87.6 \mathrm{mg} / 1,11.7 \mathrm{NTU}$, and $0.08 \mathrm{~m}$ and RRMSE of $17.8 \%, 20.5 \%$, and $27.9 \%$ for SSC, turbidity, and SDD, 


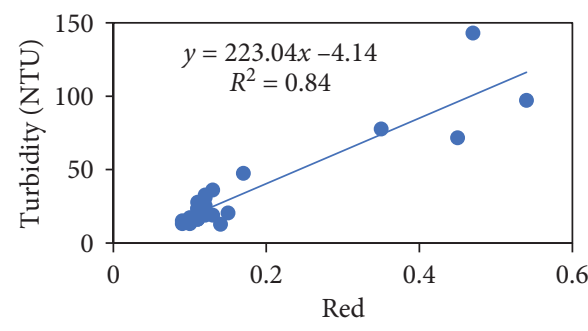

(a)

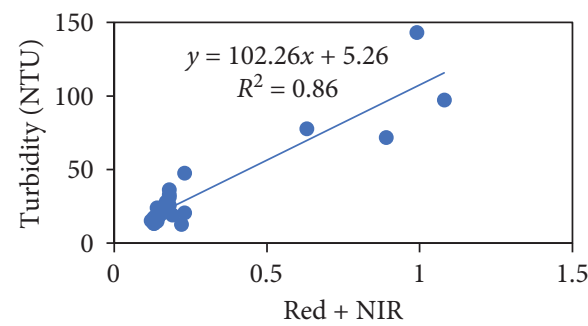

(c)

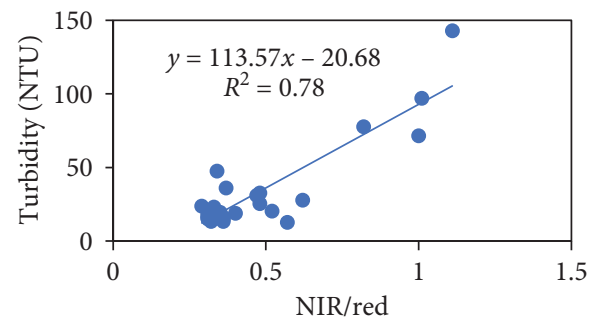

(e)

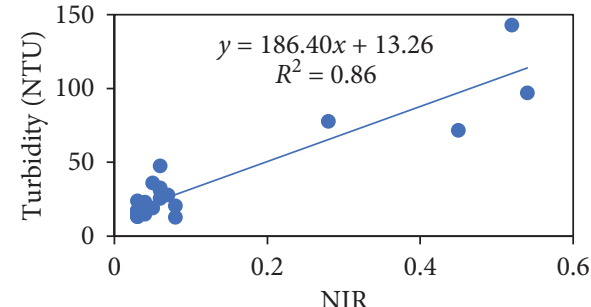

(b)

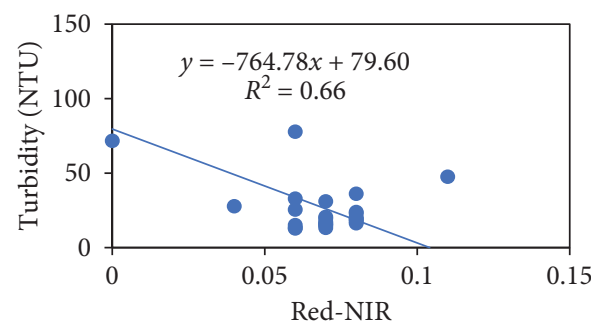

(d)

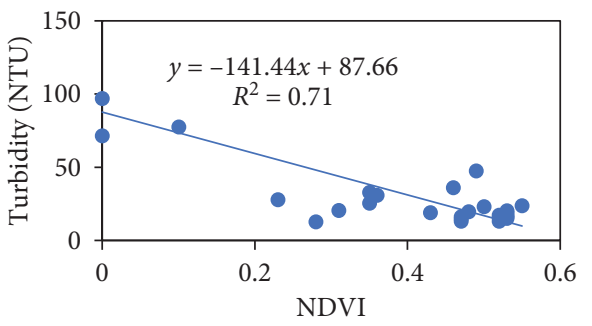

(f)

FIGURE 4: Scatter plot of measured turbidity (NTU) against MOD09GQ surface reflectance bands: (a) turbidity vs. red band; (b) turbidity vs. NIR band; (c) turbidity vs. (red + NIR) band; (d) turbidity vs. (red-NIR) band; (e) turbidity vs. (NIR/red) band; (f) turbidity vs. (red-NIR/ red + NIR) or NDVI band.

respectively. The associated residuals were distributed in between $\pm 60 \mathrm{mg} / \mathrm{l}$ for SSC, $\pm 20 \mathrm{NTU}$ for turbidity, and $\pm 0.06 \mathrm{~m}$ for SDD (Figure 7).

In contrast to previous studies, the SSC estimation error of this study was found to be relatively smaller. For instance, in the Wang and $\mathrm{Lu}[9]$ study of the lower Yangtze River in east China, SSC estimation error from the empirical model was found to be $25.5 \%, 96.1 \mathrm{mg} / \mathrm{l}$, and $36.5 \%$ for ARE, RMSE, and RRMSE, respectively, for the SSC range of $45-909 \mathrm{mg} / \mathrm{l}$. They applied the LOOCV method, and the developed empirical model at the Yangtze was used in another river named Datong resulting in SSC estimation error defined by ARE of $19.8 \%$, RMSE of $63.0 \mathrm{mg} / \mathrm{l}$, and RRMSE of $23.9 \%$. However, in this study, SSC, turbidity, and SDD estimation errors were found to be larger than estimation error reported by Kaba et al. [7] which are conducted only on the Eastern part (Gumara river inlet) to Lake Tana, Ethiopia. The estimation errors reported were MAE of $10 \%, 14 \%$, and $0.1 \%$ and RMSE of $16.5 \mathrm{mg} / \mathrm{l}, 15.6 \mathrm{NTU}$, and $0.11 \mathrm{~m}$ for the TSS, turbidity, and SDD. Moreover, SSC estimation error characterized by the RMSE of $11.20 \mathrm{mg} / \mathrm{l}$ and RRMSE of $28.6 \%$ for SSC range $0-141 \mathrm{mg} / \mathrm{l}$ reported by Cui et al. [1] was found to be relatively lower.

The possible cause of the large error is the high variability of the sediment dynamics in the tributary rivers of the lake (i.e., Gilgel Abbay, Gumara, Rib, and Megech). Such high variability of the SSC spatiotemporal distribution means that even small discrepancies between the time of in situ data collection and the time of satellite overpass can introduce significant differences in environmental conditions. Given the logistical challenges of collecting samples at multiple points around the $3000 \mathrm{~km}^{2}$ lake, it is not possible to meet the time of all data collection to match with the 10:30 a.m. local overpass time of the Terra satellite.

In addition, particle size distribution can affect the SSC vs. reflectance relation. The size of suspended particles can vary with time and location across the lake and smaller sized sediments and generally leads to a higher spectral reflectance for similar SSC values [7, 9]. A linear relation between SSC and turbidity with water reflectance and nonlinear relation between Secchi disc depth with water reflectance are tested for Lake Tana. This study also found that water reflectance of MODIS-Terra daily (MOD09GQ) Band 2 (NIR) showed a linear relationship with the range of $107.6-1661.3 \mathrm{mg} / \mathrm{l}$ for SSC, 7.3-558 NTU for turbidity, and a nonlinear relationship for SDD within the range of $0.06-1.5 \mathrm{~m}$.

The result of this study is consistent with the results of Kaba et al. [7] which reported the water reflectance of MODIS NIR with a linear relationship to TSS and turbidity and the relationship for SDD as nonlinear at the inlet of Gumara river. In 


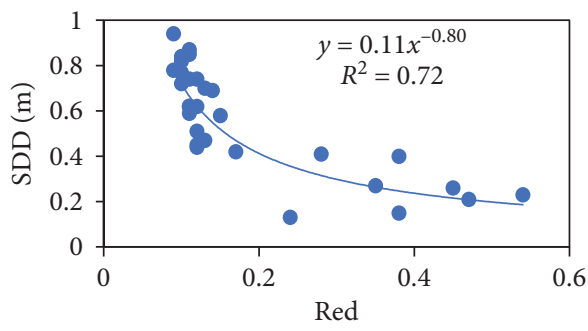

(a)

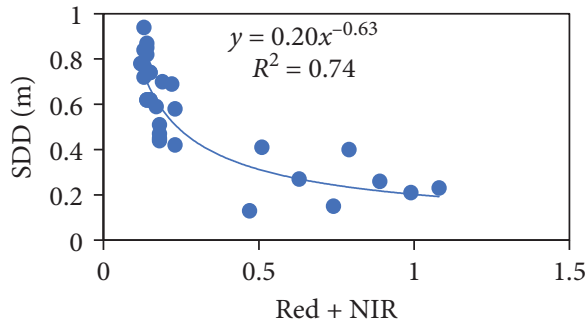

(c)

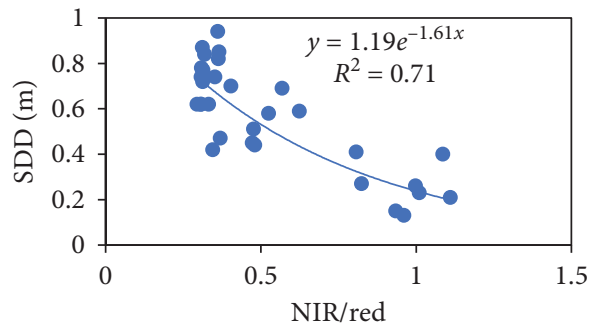

(e)

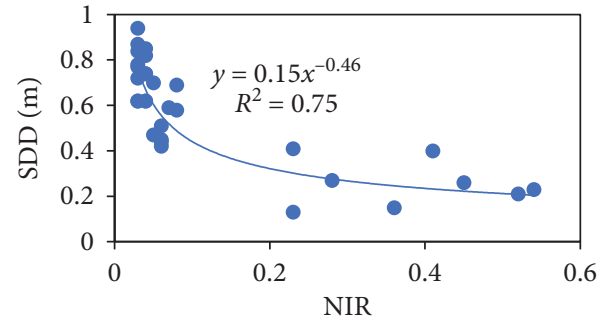

(b)

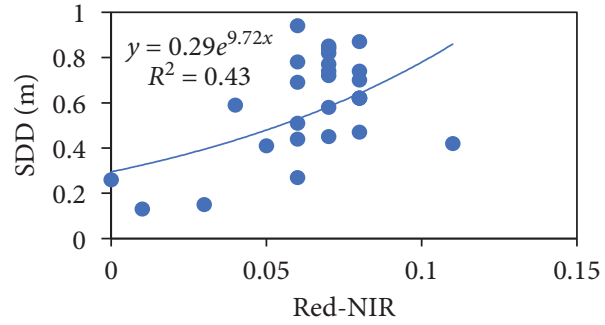

(d)

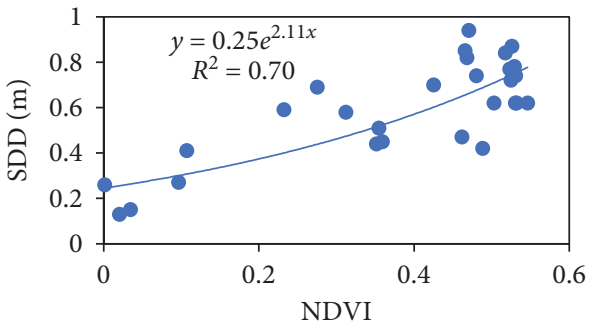

(f)

FIGURE 5: Scatter plot of observed SDD (m) against MOD09GQ surface reflectance bands: (a) SDD vs. red band; (b) SDD vs. NIR band; (c) SDD vs. (red + NIR) band; (d) SDD vs. (red-NIR) band; (e) SDD vs. (NIR/red) band; (f) SDD vs. (red-NIR/red + NIR) or NDVI band.

addition to a single band, reflectance ratios between band 1 and band 2 of Landsat-7 ETM + have also been proposed to indicate turbidity for Lake Tana near Gumara River [8]. Doxaran et al. [18] pointed out that the use of reflectance ratios could reduce skylight reflection and the influence of particle grain-size and refractive index variations. However, in this study, the red band along with band sum, difference, and ratios was used to exploit any advantage in improving the model, and in this study, it did not show a good relation with SSC, turbidity, and SDD. It resulted in a lower $R^{2}$ value as compared with a single NIR band. A possible reason may be that atmospheric correction was not as effective at the NIR band, such that more residual atmospheric effects may remain [15].

A strong correlation between observed SSC and turbidity $\left(R^{2}=0.76\right)$ was observed (Figure 8), and this suggests that turbidity in the lake is mainly due to suspended sediment and not the inflow of color causing dissolved materials. As the upper watersheds are predominantly intensively cultivated lands [8], the inflow of color causing agents is minimal [7]. However, continued cultivation practice and subsequent flow into the lake will facilitate the rapid growth of microscopic algae or cyanobacteria in water resulting in biological turbidity. Nevertheless, during the rainy period, it was observed that Lake Tana is relatively free of algal particles [5].
3.3. Generating SSC Time Series Data for Lake Tana. A 10year time span of MODIS NIR image was downloaded from 2008 to 2017 from USGS site via AppEEARS corresponding to the sampling dates. Cloud contaminated MODIS daily surface reflectance NIR images were excluded from the analysis. The time series plot of SSC estimated over Lake Tana for the month of May-August from 2008-2017 images is shown in Figure 9. The seasonal effect of the estimated SSC time series was removed with decomposition of a time series using $R$ software. The Mann-Kendall nonparametric Trend Test $[31,32]$ was used to analyze the data estimated over time either for consistently increasing or decreasing trends ("monotonic trends"). Peak concentration in the lake showed an increasing trend in the 2008-2017 periods. As the computed $p$ value 0.03 is lower than the significance level alpha $=0.05$, the null hypothesis was rejected and the alternative hypothesis is accepted in favor of the increasing trend in the series during the rainy seasons. The result of the trend test was consistent with a study conducted by Moges et al. [8], which found an increasing trend in turbidity from the period 1999 to 2014 .

The occurrence of SSC peak before flow peak is attributed to the soil properties that are loose erodible sediment at the beginning of the rainy season because of ploughing (see Zimale et al. [3]). At the start of the rainy season, the loose 


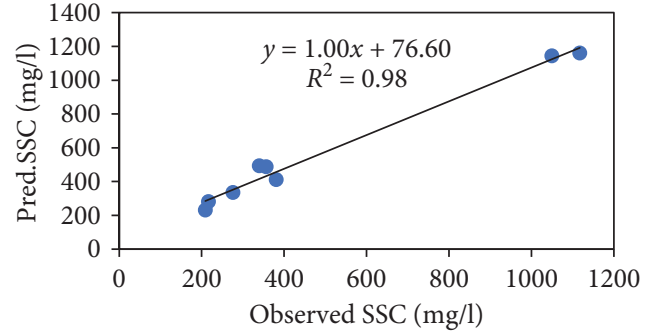

(a)

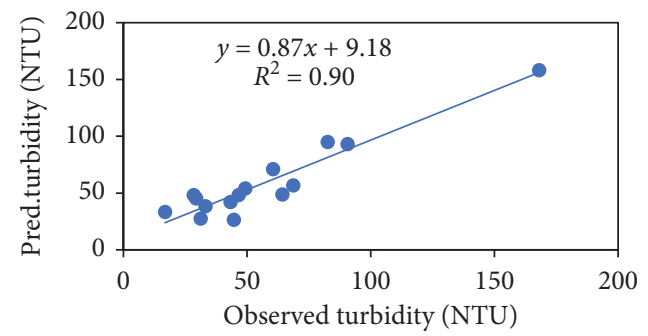

(c)

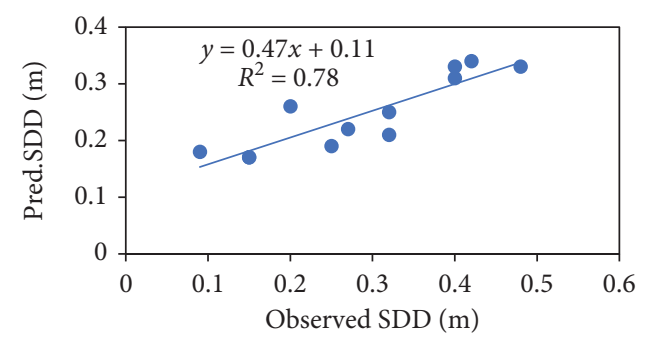

(e)

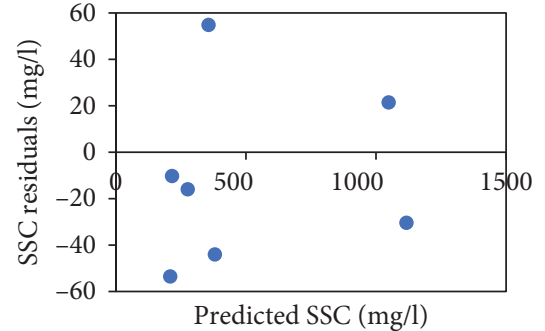

(b)

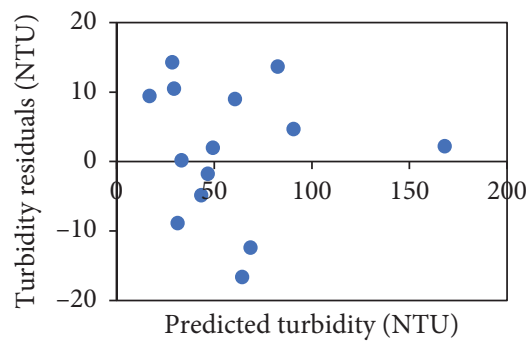

(d)

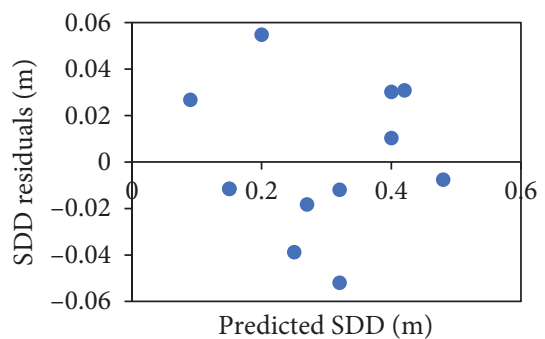

(f)

FIGURE 6: LOOCV of the calibrated model between in situ observed and MOD09GQ NIR band reflectance and associated residuals of measured and predicted SSC, turbidity, and SDD: (a) observed vs. predicted SSC; (b) observed vs. residual SSC; (c) observed vs. predicted turbidity; (d) observed vs. residual turbidity; (e) observed vs. predicted SDD; (f) observed vs. residual SDD.

soil in the watersheds that are easily washed off cause the sediment concentrations peak before the rainy season gets fully underway. Sediment concentrations in rivers at the beginning of the monsoon season are high and then decrease gradually [33, 34]. Zimale et al. [3] also reported that sediment concentration decreases at the end of the monsoon rainy season. Moreover, as the rainy season continues, the soil becomes more cohesive and base flow begins to contribute to streamflow, diluting the sediment $[33,34]$. The runoff water then spreads over the river delta dropping the sediment load and contributes to delta development along the lakeshore $[3,8,25,35]$.

\section{Discussion}

4.1. Spatiotemporal Distribution of SSC in Lake Tana. Spatial and temporal suspended sediment variation can be driven by both anthropogenic and natural factors within the lake basins and could also be affected by soil erosion within a lake contributing basin through surface water inputs. The spreading of suspended sediment from river mouths to the lake appears less turbid before the beginning of the rainy season in May. Before the start of rainy season, discharging rivers to Lake Tana (Gilgel Abbay river in the southwest, Gumara and Rib river in the east, and Megech and ArnoGarno river in the northeast) was relatively free of suspended sediment and clean (Figure 10(a)). During this period, the most likely turbidity plume was due to the shoreline erosion, and when compared with other periods, the SSC observed was lower. In the dry monsoon season, sediment concentrations are low [3]. As the rainy season begins and continues, reddish turbid plumes at the entry location of Gilgel Abbay river in the southwest and Gumara and Rib rivers in the east are seen in June (Figure 10(b)). At the start of the rainy season, the turbidity plume was due to suspended sediment load from draining rivers. Elevated sediment concentration occurs during the rainy season (June, July, and August) [3]. The reddish plume due to suspended sediment spreads as the rainy season continues along the shore of the lake over a wide area as seen in July and August (Figures 10(c) and 10(d)). In addition, flood plains all around the lake were flooded and drained into the lake during the rainy season [2] contributing to the suspended sediment load to the lake. Hence, the increase in SSC reduces the primary productions [2] and enhances the siltation of the reservoirs and lakes [3]. As the rainy season concludes, the 


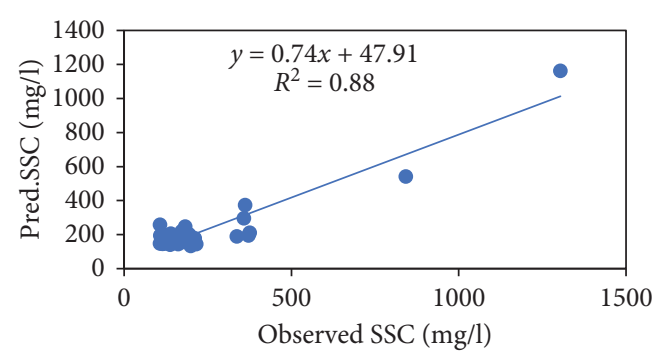

(a)

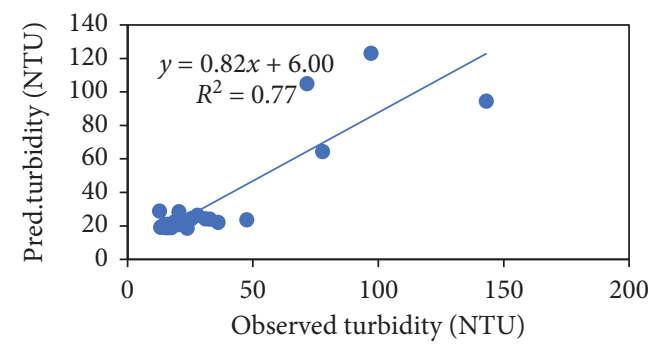

(c)

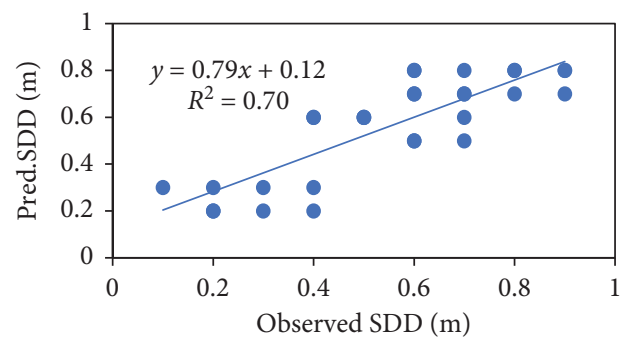

(e)

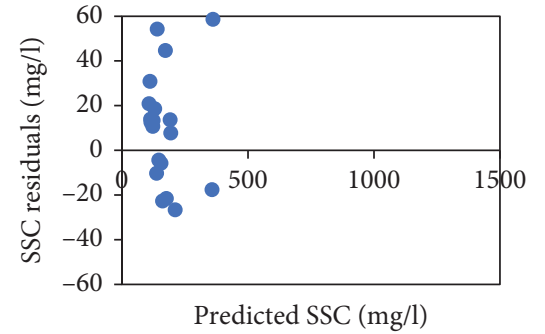

(b)

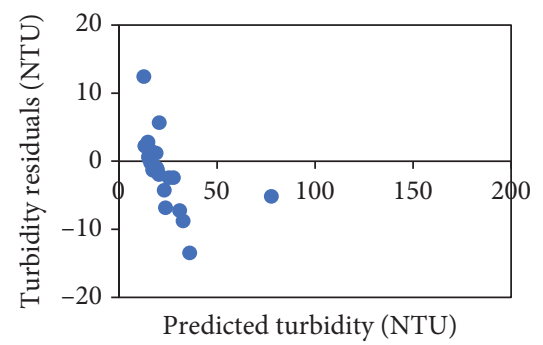

(d)

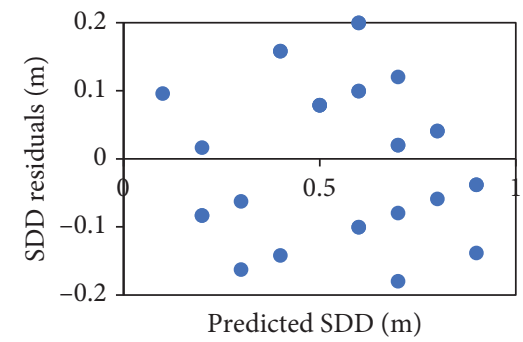

(f)

FIGURE 7: Validation of SSC, turbidity, and SDD for August 2018 data sets and associated residuals: (a) observed vs. predicted SSC; (b) observed vs. residual SSC; (c) observed vs. predicted turbidity; (d) observed vs. residual turbidity; (e) observed vs. predicted SDD; (f) observed vs. residual SDD.

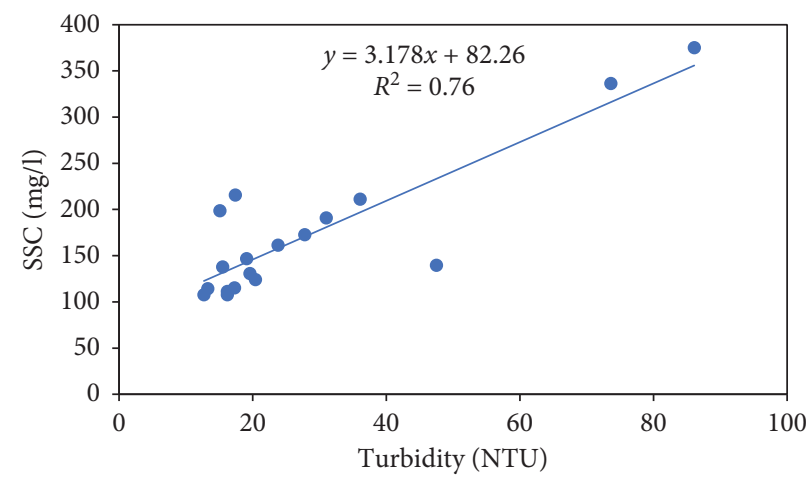

FIGURE 8: A scatter plot of the relationship between in situ observed SSC (mg/l) and turbidity (NTU) results over the surface of Lake Tana from June 2018 observation.

turbid plume spreading decreases over the surface area of the lake as shown in Figures 10(e) and 10(f)

The importance of sediment deposition in streams and on its bank is attributed to land degradation in the upper catchment [25]. Moges et al. [36], Steenhuis et al. [37], Tilahun et al. [38], and Zimale et al. [3] reported that degraded and saturated areas were the main contributing runoff areas and hence were found to be sources for sediment concentrations. Moges et al. [36] and Zimale et al. [3] reported that most of the sediments were generated from degraded areas. The sediment that is lost from the saturated area is likely from the gullies that are found 


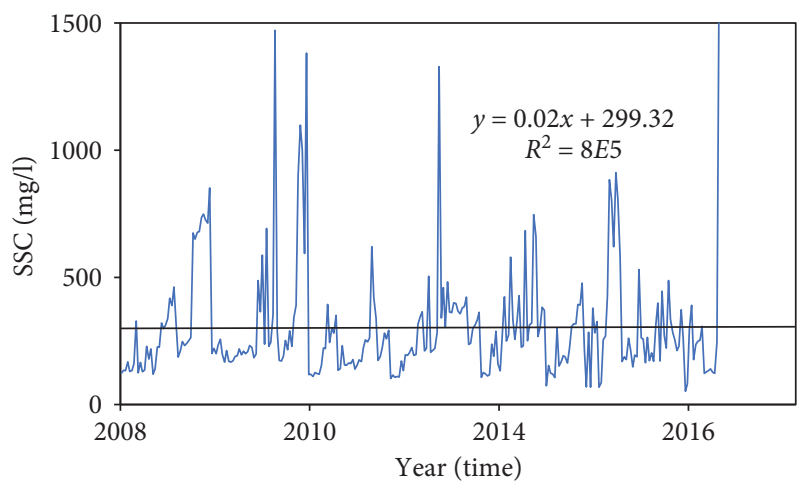

FIGURE 9: Plot of estimated time series of SSC (mg/l) from 2008-2017 images corresponding to the sampled dates over Lake Tana using the developed model.

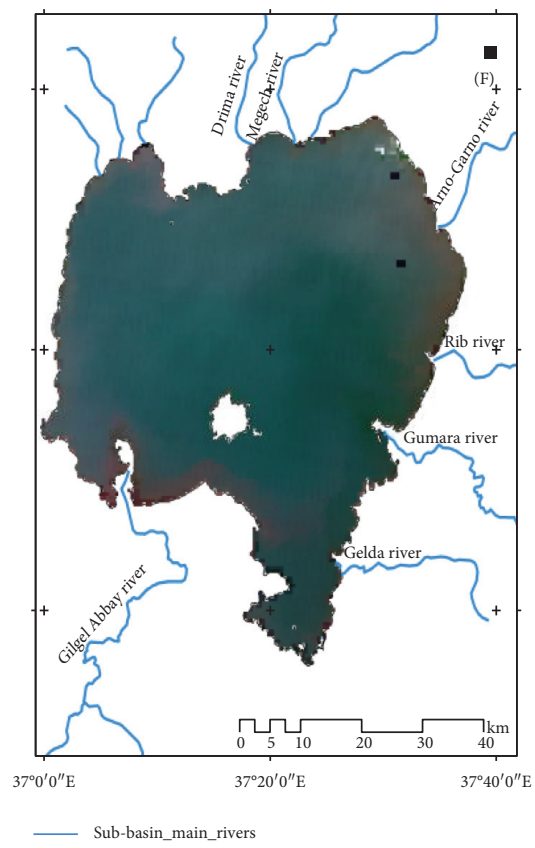

(a)

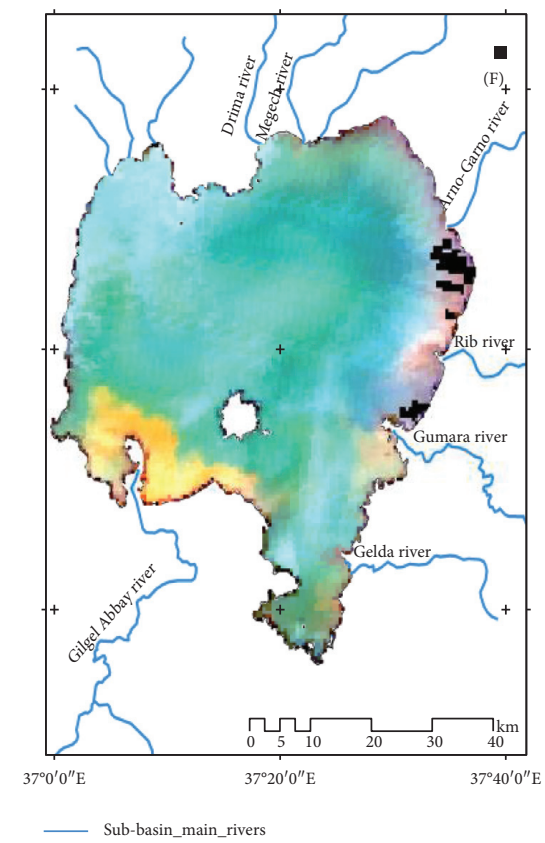

(b)

Figure 10: Continued. 


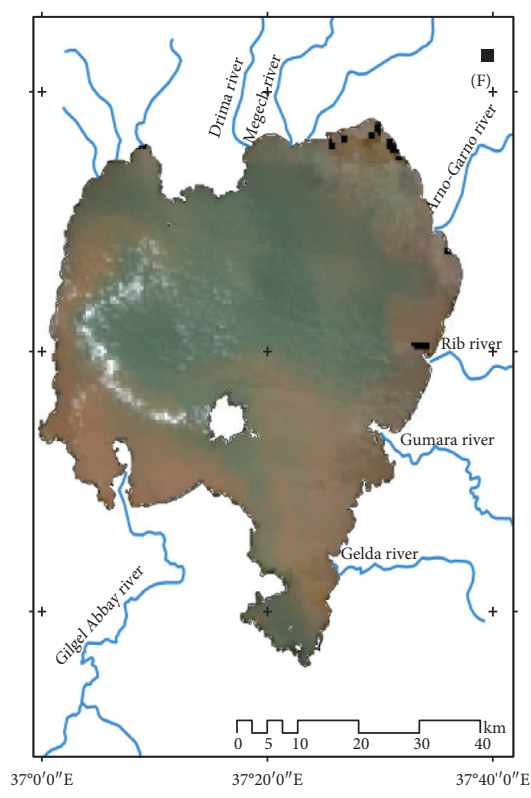

_ Sub-basin_main_rivers

(c)

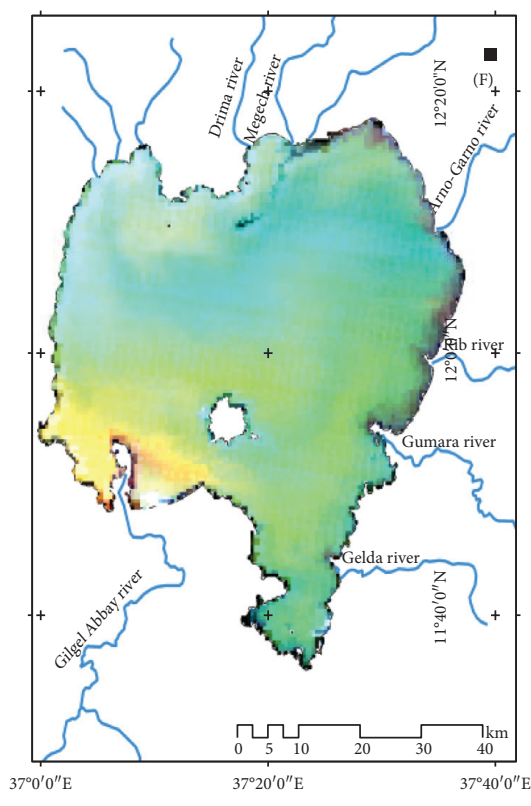

_- Sub-basin_main_rivers

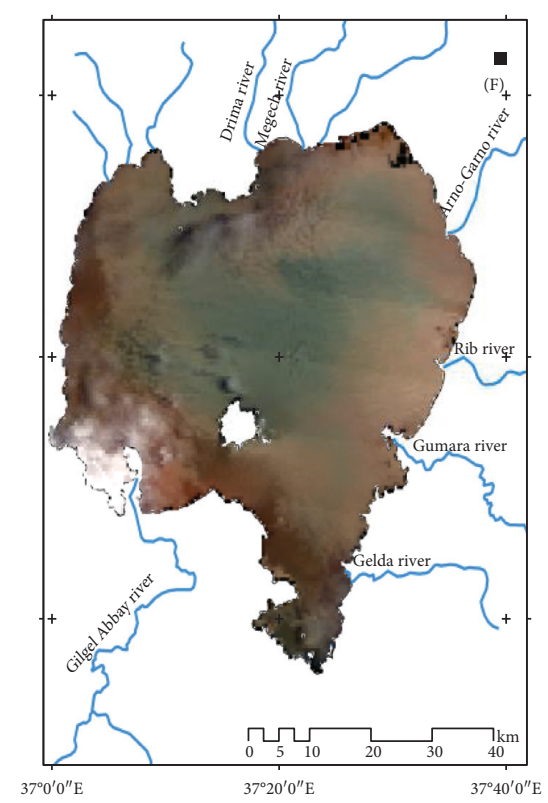

_ Sub-basin_main_rivers

(d)

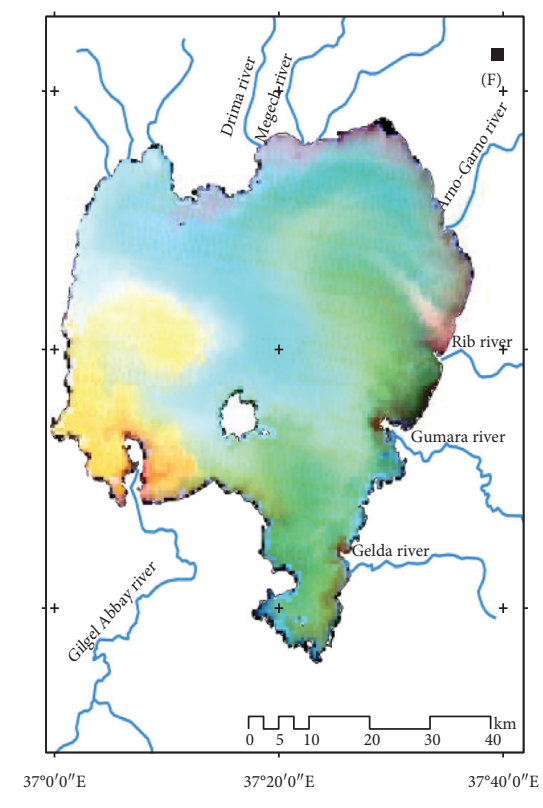

— Sub-basin_main_rivers

(f)

Figure 10: MOD09GA band 1, 4, and 3 false color image combinations showing turbid plume spreading from rivers to Lake Tana on and around the sampling dates: (a) 13 May 2018; (b) 10 June 2018; (c) 14 July 2018; (d) 15 August 2018; (e) 27 September 2018; (f) 27 October 2018.

in the gradually saturated bottomlands especially at the end of the rainy season $[33,38]$. In the rainy season, the sediment coming from both degraded and saturated runoff source areas of the lake basins has higher impacts on the water quality of Lake Tana causing higher turbidity or SSC. Relatively higher suspended sediment concentration was observed in the west and east part of the lake during the rainy season (Figures 11(a), 11(b), and 12). The 

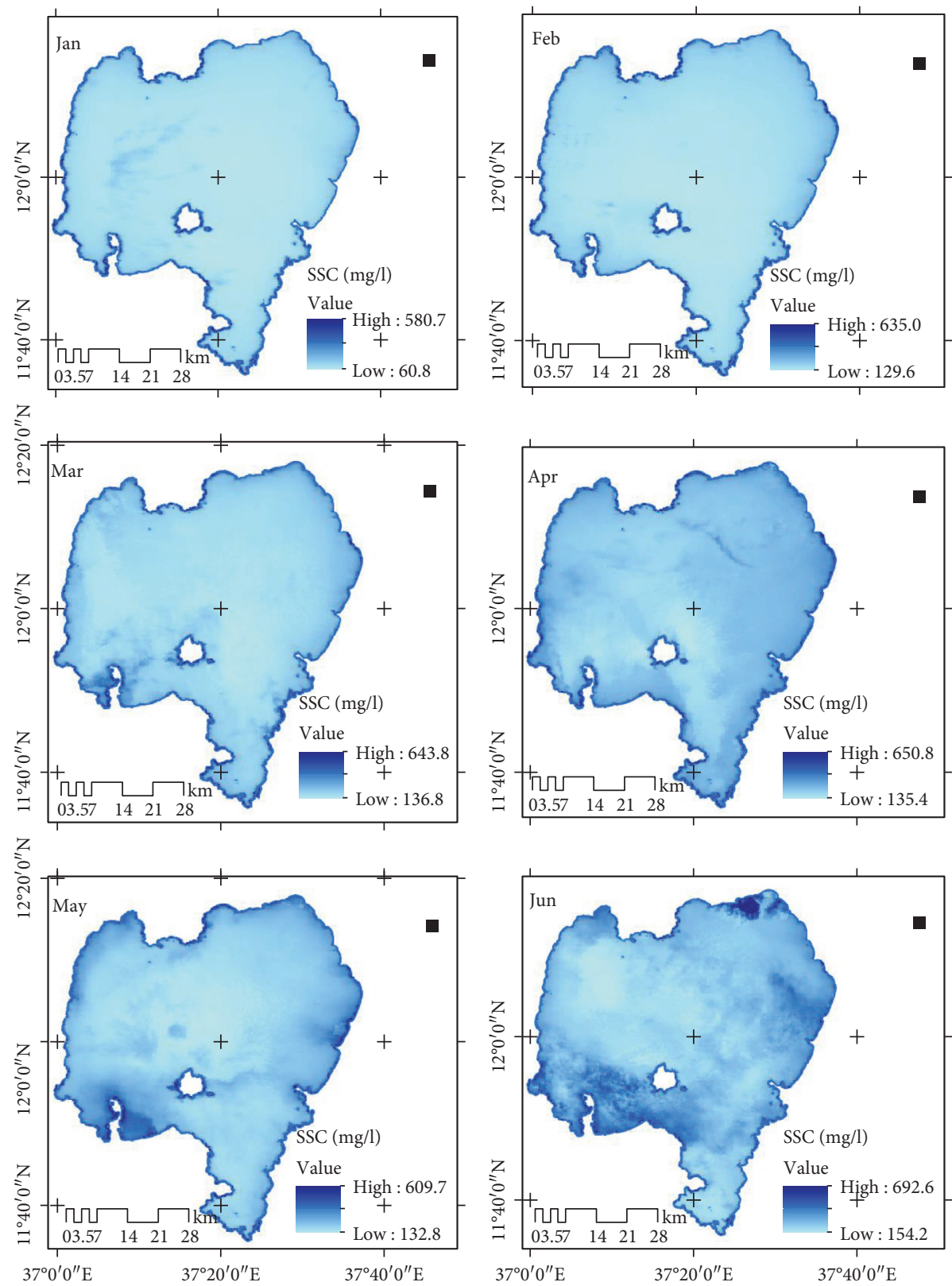

(a)

FIgure 11: Continued. 

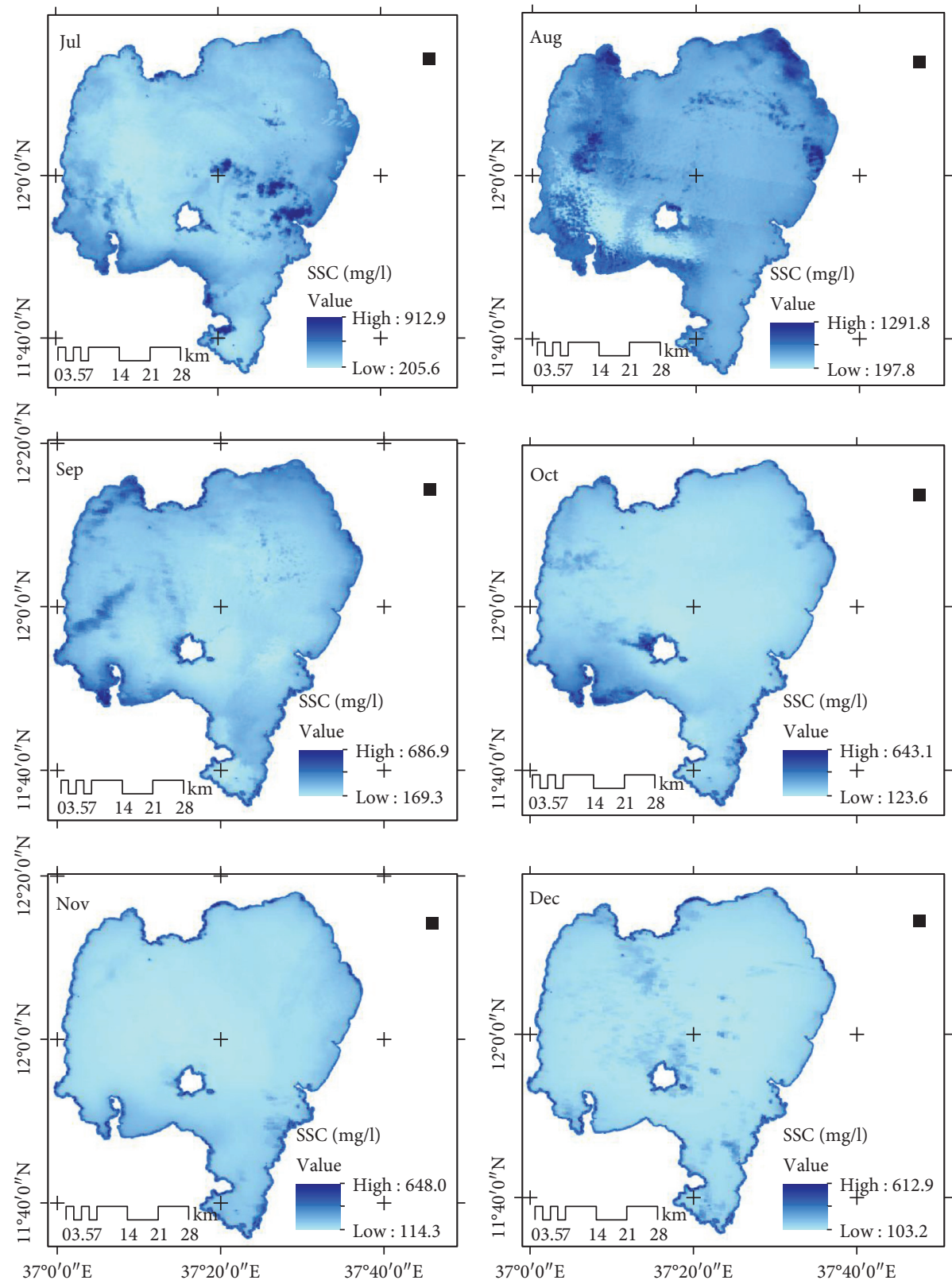

(b)

FIGURE 11: Spatiotemporal distribution of mean monthly SSC from (a) Jan-Jun 2014 and (b) Jul-Dec 2014 generated by the developed retrieval model.

higher sediment concentration was contributed by major tributary rivers of the Lake Tana Basins (Gilgel Abbay, Gumara, Rib, and Megech rivers). Moderate suspended sediment concentrations were observed in the central part of the lake.

Lake Tana has importance for the local and aquatic community as much of the people and aquatic life surrounding the lake depends on it. However, the findings of this study indicated that the water quality of the lake is deteriorating in space and time. Management measures need to be implemented in the upper part of the watersheds to reduce the sediment inflow to the lake. Measures also need proper study according to the degree of degradation. Soil and water conservation interventions 

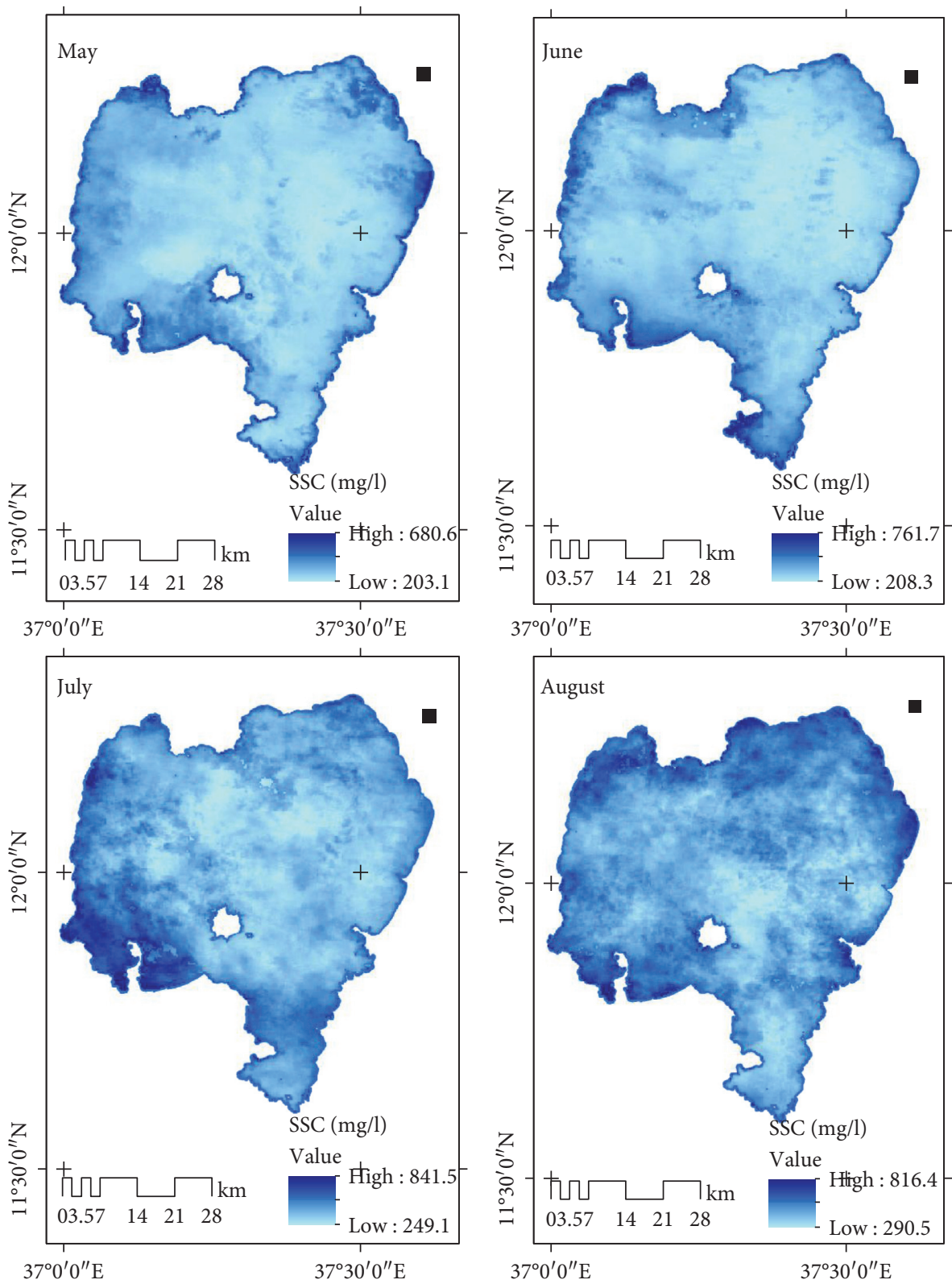

FIGURE 12: Spatiotemporal distribution of mean suspended sediment concentration generated from the developed SSC model on Lake Tana in May, June, July, and August 2018.

including the physical, biological, and agronomic measures should be installed to reduce sediment load inflow to the Lake. In addition, the integrated use of these three measures benefits the most in reducing sediment deposition.

\section{Conclusion}

Availability of MODIS-Terra daily remotely sensed imagery makes it possible to monitor the sediment dynamics of Lake Tana especially during the rainy or wet season, during which peak sediment concentration arrives at the lake. A strong statistical relationship was observed between SSC, turbidity, and SDD and MODIS-Terra daily remotely sensed reflectance over Lake Tana. The established retrieval models can be used to provide water quality monitoring. Thus, the application of MODIS-Terra daily imagery takes the place of other satellite images due to its much higher temporal resolution. The constructed regression equations were used to retrieve SSC time series for 10 years, and it was found that the peak concentration of suspended sediment has an increasing trend, deteriorating the water quality of Lake Tana.

\section{Data Availability}

The data used for the research are available from the corresponding author upon request (fasikaw@gmail.com). 


\section{Conflicts of Interest}

The authors declare that they have no conflicts of interest.

\section{References}

[1] L. Cui, Y. Qiu, T. Fei, Y. Liu, and G. Wu, "Using remotely sensed suspended sediment concentration variation to improve management of Poyang lake, China," Lake and Reservoir Management, vol. 29, no. 1, pp. 47-60, 2013.

[2] J. Vijverberg, F. A. Sibbing, and E. Dejen, "Lake Tana: source of the blue nile," in The Nile, pp. 163-192, Springer, Netherlands, NY, USA, 2009.

[3] F. A. Zimale, M. A. Moges, M. L. Alemu et al., "Budgeting suspended sediment fluxes in tropical monsoonal watersheds with limited data: the lake tana basin," Journal of Hydrology and Hydromechanics, vol. 66, pp. 65-78, 2018.

[4] A. Moridnejad, H. Abdollahi, S. K. Alavipanah, J. M. V. Samani, O. Moridnejad, and N. Karimi, "Applying artificial neural networks to estimate suspended sediment concentrations along the southern coast of the caspian sea using MODIS images," Arabian Journal of Geosciences, vol. 8, no. 2, pp. 891-901, 2015.

[5] T. T. Danbara, Deriving Water Quality Indicators of Lake Tana, Ethiopia, from Landsat-8, University of Twente Faculty of Geo-information and Earth Observation (ITC), Enschede, Netherlands, 2014.

[6] X. Jiang, J. Tang, M. Zhang, R. Ma, and J. Ding, “Application of MODIS data in monitoring suspended sediment of Taihu lake, China," Chinese Journal of Oceanology and Limnology, vol. 27, no. 3, pp. 614-620, 2009.

[7] E. Kaba, W. Philpot, and T. Steenhuis, "Evaluating suitability of MODIS-Terra images for reproducing historic sediment concentrations in water bodies: lake tana, Ethiopia," International Journal of Applied Earth Observation and Geoinformation, vol. 26, pp. 286-297, 2014.

[8] M. A. Moges, P. Schmitter, S. A. Tilahun et al., "Water quality assessment by measuring and using landsat 7 ETM+ images for the current and previous trend perspective: lake tana Ethiopia," Journal of Water Resource and Protection, vol. 9, no. 12 , pp. $1564-1585,2017 \mathrm{~b}$.

[9] J.-J. Wang and X. Lu, "Estimation of suspended sediment concentrations using Terra MODIS: an example from the lower Yangtze river, China," The Science of the Total Environment, vol. 408, pp. 1131-1138, 2010.

[10] R. L. Miller and B. A. McKee, "Using MODIS Terra $250 \mathrm{~m}$ imagery to map concentrations of total suspended matter in coastal waters," Remote Sensing of Environment, vol. 93, no. 12, pp. 259-266, 2004.

[11] C. Wang, W. Li, S. Chen, D. Li, D. Wang, and J. Liu, "The spatial and temporal variation of total suspended solid concentration in pearl river estuary during 1987-2015 based on remote sensing," The Science of the Total Environment, vol. 618, pp. 1125-1138, 2018.

[12] C. Hu, Z. Chen, T. D. Clayton, P. Swarzenski, J. C. Brock, and F. E. Muller-Karger, "Assessment of estuarine water-quality indicators using MODIS medium-resolution bands: initial results from Tampa bay, FL," Remote Sensing of Environment, vol. 93, no. 3, pp. 423-441, 2004.

[13] R. Ma, J. Tang, and J. Dai, "Bio-optical model with optimal parameter suitable for Taihu lake in water colour remote sensing," International Journal of Remote Sensing, vol. 27, no. 19, pp. 4305-4328, 2006.
[14] M. I. Shahzad, M. Meraj, M. Nazeer et al., "Empirical estimation of suspended solids concentration in the indus delta region using landsat-7 ETM+ imagery," Journal of Environmental Management, vol. 209, pp. 254-261, 2018.

[15] J.-J. Wang, X. X. Lu, S. C. Liew, and Y. Zhou, "Retrieval of suspended sediment concentrations in large turbid rivers using landsat ETM+: an example from the Yangtze river, China," Earth Surface Processes and Landforms, vol. 34, pp. 1082-1092, 2009.

[16] M. Wu, W. Zhang, X. Wang, and D. Luo, "Application of MODIS satellite data in monitoring water quality parameters of Chaohu lake in China," Environmental Monitoring and Assessment, vol. 148, pp. 255-264, 2009.

[17] G. Wu, L. Cui, H. Duan, T. Fei, and Y. Liu, "An approach for developing Landsat-5 TM-based retrieval models of suspended particulate matter concentration with the assistance of MODIS," Journal of Photogrammetry and Remote Sensing, vol. 8, pp. 84-92, 2013.

[18] D. Doxaran, J.-M. Froidefond, S. Lavender, and P. Castaing, "Spectral signature of highly turbid waters," Remote Sensing of Environment, vol. 81, no. 1, pp. 149-161, 2002.

[19] J. C. Ritchie, P. V. Zimba, and J. H. Everitt, "Remote sensing techniques to assess water quality," Photogrammetric Engineering \& Remote Sensing, vol. 69, no. 6, pp. 695-704, 2003.

[20] P. Härmä, J. Vepsäläinen, T. Hannonen et al., "Detection of water quality using simulated satellite data and semi-empirical algorithms in Finland," The Science of the Total Environment, vol. 268, no. 1-3, pp. 107-121, 2001.

[21] M. Zhang, Q. Dong, T. Cui, C. Xue, and S. Zhang, "Suspended sediment monitoring and assessment for yellow river estuary from landsat TM and ETM + imagery," Remote Sensing of Environment, vol. 146, pp. 136-147, 2014.

[22] A. G. Dekker, H. J. Hoogenboom, L. M. Goddijn, and T. J. M. Malthus, "The relation between inherent optical properties and reflectance spectra in turbid inland waters," Remote Sensing Reviews, vol. 15, no. 1-4, pp. 59-74, 1997.

[23] A. G. Dekker, R. J. Vos, and S. W. M. Peters, "Comparison of remote sensing data, model results and in situ data for total suspended matter (TSM) in the southern Frisian lakes," The Science of the Total Environment, vol. 268, no. 1-3, pp. 197214, 2001.

[24] T. Alemayehu, M. McCartney, and S. Kebede, "The water resource implications of planned development in the lake tana catchment, Ethiopia," Ecohydrology and Hydrobiology, vol. 10, no. 2-4, pp. 211-221, 2010.

[25] M. Abate, J. Nyssen, T. S. Steenhuis et al., "Morphological changes of Gumara river channel over 50 years, upper blue nile basin, Ethiopia," Journal of Hydrology, vol. 525, pp. 152-164, 2015.

[26] D. C. Dagnew, C. D. Guzman, A. D. Zegeye et al., "Sediment loss patterns in the sub-humid Ethiopian highlands," Land Degradation \& Development, vol. 28, no. 6, pp. 1795-1805, 2016.

[27] A. M. Beeton, "Relationship between secchi disc readings and light penetration in lake Huron," Transactions of the American Fisheries Society, vol. 87, no. 1, pp. 73-79, 1958.

[28] T. A. Walker, "Use of a Secchi disc to measure attenuation of underwater light for photosynthesis," Journal of Applied Ecology, vol. 19, pp. 539-543, 1982.

[29] E. Vermote and R. Wolfe, "MOD09GQ MODIS/Terra surface reflectance daily L2G global $250 \mathrm{~m}$ sin grid v006," NASA EOSDIS Land Processes DAAC, vol. 10, 2015b. 
[30] E. Vermote and R. Wolfe, "MOD09GA MODIS/terra surface reflectance daily L2G global $1 \mathrm{~km}$ and $500 \mathrm{~m}$ SIN grid V006," NASA EOSDIS Land Processes DAAC, vol. 10, 2015a.

[31] H. B. Mann, "Nonparametric tests against trend," Econometrica, vol. 13, no. 3, pp. 245-259, 1945.

[32] M. Kendall, Rank Correlation Methods, Charles Griffin, London, 1975.

[33] S. A. Tilahun, C. D. Guzman, A. D. Zegeye et al., "An efficient semi-distributed hillslope erosion model for the subhumid Ethiopian Highlands," Hydrology and Earth System Sciences, vol. 17, no. 3, pp. 1051-1063, 2013a.

[34] S. A. Tilahun, R. Mukundan, B. A. Demisse et al., "A saturation excess erosion model," Transactions of the American Society of Agricultural and Biological Engineers, vol. 56, pp. 681-695, 2013b.

[35] M. Kebedew, S. Tilahun, M. Belete, F. Zimale, and T. Steenhuis, "Sediment deposition (1940-2017) in a historically pristine lake in a rapidly developing tropical highland region in Ethiopia," Earth Surface Processes and Landforms, vol. 46, pp. 1521-1535, 2021.

[36] M. A. Moges, P. Schmitter, S. A. Tilahun, and T. S. Steenhuis, "Watershed modeling for reducing future non-point source sediment and phosphorus load in the Lake Tana basin, Ethiopia," Journal of Soils and Sediments, vol. 18, no. 1, pp. 309-322, 2017a.

[37] T. S. Steenhuis, S. A. Tilahun, Z. K. Tesemma et al., "Soil erosion and discharge in the blue nile basin: trends and challenges," Nile River Basin, Springer, Berlin, Germany, pp. 133-147, 2014.

[38] S. A. Tilahun, C. D. Guzman, A. D. Zegeye et al., "Spatial and temporal patterns of soil erosion in the semi-humid Ethiopian highlands: a case study of Debre Mawi watershed," Nile River Basin, Springer, Berlin, Germany, pp. 149-163, 2014. 